\title{
THE VALUE OF MOTHERHOOD: PAID MATERNITY LEAVE DISCOURSE IN MAJOR U.S. MEDIA OUTLETS IN THE YEARS 2014-2018
}

\author{
ALEKSANDRA RABENDA-NOWAK \\ Institute of History, Vistula University \\ ul. Stokłosy 3, 02-787 Warszawa, Poland \\ E-mail address: rabenda.ola@gmail.com \\ ORCID ID: https://orcid.org/0000-0001-5281-2703
}

\begin{abstract}
Aim. This article's goal is to present the discourse concerning paid maternity leaves in the USA in major American media outlets between the years 2014 and 2018. It is an attempt to answer the question whether maternity, caregiving work or family values are contradictory to American work ethic and regulations of the labour market.

Methodology. The work is devoted to content analysis of the four most popular American online media, both liberal and conservative. Their content search engines are used to find information and articles on paid maternity leaves and to group them into different categories.

Results. Three main categories are distinguished in terms of the content of 302 articles, namely articles with a positive attitude towards paid maternity leaves ( 248 articles $-82.10 \%$ ), articles with a negative attitude (20 articles $-6.60 \%)$, and neutral articles (34 $-11.30 \%$ ). In general, Americans see the long-term benefits of paid maternity leaves, but they differ when it comes to the methods of their introduction.

Conclusions. There is a conflict between maternity, family values, American work culture, and regulations of the labour market. In American society, individualism, competition, and masculinity of the business culture do not support the values of nurturing and caregiving.

Originality. Except for the USA, there is no other country among OECD states which does not provide paid parental leaves for working mothers. Because of the fact that the United States is known to be one of the most developed countries in the world, this information may be considered worth-studying.

Key words: Maternity, paid maternity leave, social policy, family, parental leaves,
\end{abstract} American society, media

\section{INTRODUCTION}

11 mericans greatly value the ideal of motherhood, and we also greatly value the work ethic. But we often find it difficult to value both at once" - this opening quotation by Stephanie Coontz (2011, p. 179) is a perfect illu-

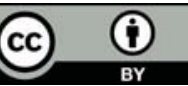


stration of American society's approach to the value of caregiving and paid benefits for working mothers. The United States is still far behind other developed countries when it comes to providing paid maternity leaves for working mothers, even though the importance of hard work and family values have always been appreciated in this country. It may seem that either there is a strong conflict between caregiving, or more broadly, between family values and work culture in the United States, or that the perception of their reconciliation differs drastically from other cultures.

In the United States of America, there is no universally offered paid maternity leave, which makes this country the only one among OECD states - and one of the very few in the world - that does not deliver such policy for its citizens (Statista.com, 2018). Taking into consideration the fact that the USA is known to be one of the most modern and developed countries in the world, the above-mentioned information may be considered as intriguing if not shocking, and the topic itself seems worth investigating. Thus, the most important aim of this work is to depict dominating narratives in the U.S. public domain on the topic of paid maternity leaves. The following questions were posed: what attitudes dominate and what solutions are proposed (if any)? How is the problem presented and what is considered to be a major obstacle for (not) introducing universal paid parental leaves in the USA for working mothers?

To start with, while discussing paid maternity leave policies in the USA, one needs to bear in mind that the term "paid maternity leave" will often be used interchangeably with "paid parental leave" in this paper, as most benefits for working parents are provided in an equal way for all employees of both sexes. Also, the term "maternity leave" itself is to be considered as the so-called "umbrella concept." In other words, there is no paid maternity leave as such in the USA that would be guaranteed by the federal government. However, there are many different policies at the federal and state level, as well as in the public and private sector, which help women go through giving birth and raising their children. They will be shortly described at the beginning of this article, in order to provide a full picture of the situation regarding social benefits in the USA.

First of all, when it comes to the scholarly literature on the topic of paid maternity leaves, it is crucial to notice that it is situated in a broader context of family, social policy, and the idea of a welfare state as a whole. Thus, in order to understand the situation of women in the USA, it is important to examine the dynamics of the American welfare state, Americans' attitudes towards governmental intervention in the matter of social benefits, or the idea of work ethic in the United States in general. All of the below-mentioned works are important in terms of presenting the background of American women's situation in the labour market, as well as popular opinions regarding female employees in the USA. Moreover, the authors of the works cited below help to show certain trends and patterns in female employment which, as this article suggests, have not changed over time and are confirmed by this article's findings. Through 
the mentioned scholarly literature, it is possible to present both the change and continuity in female employment trends in the United States. What is more, most of the scholarly texts used here are a vital source of professional data concerning both government and employers' activity in the scope of parental policies, which were also very useful to the author.

There are many eminent scholars who studied welfare state regimes in different countries, including the United States. Among the most notable ones who specifically examined gender in their research are Diane Sainsbury and Mary Daly in their Gender and welfare state regimes (1996). Their book examines the construction of gender in welfare policies of different governments and illustrates how given traits of welfare state regimes reinforce or weaken gender inequalities. They argue, for example, that social policies of different governments may not respond to working mothers' needs, as workplace is mainly regarded as the men's world. Another important source to study paid parental leaves in the USA is The politics of social policy in the United States by Margaret Weir, Ann Schola Orloff, and Theda Skocpol (1988), which gives a historical overview of Americans' attitudes towards the welfare state and social policies implemented by the government. It analyses the welfare debates of the 1980s in the context of past American social policies, arguing that there was a backlash against "big government" that followed 1960s and 1970s reforms. Moreover, in Democracy and the welfare state, Amy Gutman (1988) researches the moral foundations, as well as political and economic prospects of the welfare state in the USA. She explores the issue of discrimination against women in the American welfare state and asks the question of why it exists at all. Furthermore, Dorothy E. McBride and Janine A. Parry (2004) in their book Women's rights in the USA: Policy debates and gender roles examine economic inequality and dependence of women with regard to gender differences and family responsibilities. They also study governmental policies that have an influence on women's employment choices.

When it comes to the research about women's employment trends and debates about quitting the workplace by female employees, the vital sources are the following: Anne Marie Slaughter and her Unfinished business (2015), as well as Linda Hirshman's Get to work: A manifesto for women of the world (2006). The topic of work-family issues is also explored by Phyllis Moen and Patrick Roehling in The Career mystique: Cracks in the American dream (2005) or Jerry Jacobs and Cathleen Gerson's The time-divide: Work, family, and gender inequality (2004). Books about discrimination against working mothers that inspired this article are, for example, Ann Crittendon's The Price of motherhood: Why the most important job in the world is still the least valued (2001) or Linda Babcock and Sara Laschever's Women don't ask: Negotiation and the gender divide (2003).

What is more, in "Maternity leave, early maternal employment and child health and development in the US," Lawrence M. Berger, Jennifer Hill and Jane Waldfogel (2005) investigate whether women's early returns to work after childbirth impact health and development of a child. They conclude that 
children develop better when women return to work later, which is due to expanded time for doctor's visits, immunizations, or breastfeeding. There is no data concerning the long-term effects of very short parental leaves and more research needs to be done on that topic, though. On the other hand, Jacob Alex Klerman and Arleen Leibowitz (1999) in their "Job continuity among new mothers" study the employment of married mothers with preschool children and conclude that the number of working mothers rose dramatically between 1971 and 1990. However, they do not find any strong relation between state maternity leave policies and employment trends. They attribute all the changes in women's employment to demographic trends regarding age or education of women rather than to any action of the government.

Other useful documents and databases regarding paid parental leaves used in this article are for example OECD and Pew Research Centre surveys or The U.S. Office of Personnel Management reports. The above-mentioned databases are an important source of basic information regarding not only the employment and demographic trends in the USA but also Americans' attitudes towards governmental intervention in the scope of paid parental leaves.

While reading this article, it is vital to note that it has an introductory character. It is based on both author's research and the findings of different scholars who studied social policy in the USA. The paper may show some trends and sentiments in American society, but more research needs to be done in terms of the long-term effects of paid parental leaves, both for the economy as well as individual families' and parents' opinions. It is crucial to understand that changes in American politics, economy, and society are generally proceeding very fast and Americans' attitudes towards governmental intervention depend on many outside factors, which may change in time. Thus, the interpretation of the results presented in this article should be considered within the time frame provided.

To begin with, the main law that working parents should be interested in - Family and Medical Leave Act of 1993 (FMLA) - entitles new parents who work in a company of at least 50 employers over a year and 25 hours a week to unpaid parental leave. It covers both local and federal employees who can take up to 12 weeks of unpaid leave, on the condition of giving a 30-day notice to their employers before. FMLA main objective is to enable workers to take care not only of their newborns but also adopted or foster children, ill family members, or themselves. All employees are guaranteed the right to return to their jobs (except those "highly-paid," to which coming back is more restricted and under many different conditions related to the current state of a company). According to the U.S. Office of Personnel Management, the Act does not cover elected officials, part-time workers, or those who need time off for doctor's visits (OPM.gov, n.d.). As soon as the leave was mandated by the government, everyone hoped that it would expand quickly, giving more and more benefits to a greater number of people. These hopes were never materialized. 
In 1993, when the FMLA was introduced, it was the states themselves that administered the execution of the Act from the beginning. The shape of legislation depended also on bargaining agreements and employers' regulations. 18 states, such as Hawaii, Montana, Oregon, Washington, Iowa, Kansas, Minnesota, Connecticut, Maine, Massachusetts, New Hampshire, Vermont, Kentucky and Louisiana as well as the District of Columbia and Puerto Rico, have added additional leave benefits to the FMLA, including higher pay or flexible sick time (Parents.com, n.d.). But the most notable legislation changes have been introduced only by four states-New Jersey, New York, Rhode Island, and California - which now offer not only paid medical but also family leaves. Their programs are funded by payroll taxes paid by employees and administered via different disability programs, which have already existed in these states before (NCSL.org, 2016). In February 2017, these four states were joined also by Washington D.C., where paid family leave regulations were introduced and effective from July 2020.

When it comes to the private and public sector, the percentage of private-sector employees who received paid parental leaves raised from $27 \%$ in 2000 to $35 \%$ in 2018. It is important to notice that paid leave benefits vary significantly when it comes to an employee's position, seniority, or length of employment. Usually, the workers who have the highest salary because of their position get the highest benefits. For example, employees in management positions in the financial and business sector get 28 weeks of paid leave in a year, but construction workers get only 8 weeks. Also, public sector employees benefit from several regulations that allow them to keep their jobs and take care of their newly born children. Thanks to Family and Medical Leave Act, they are entitled to up to 12 weeks of unpaid leave a year, which may be prolonged (BLS.gov, 2020). Another document, the Presidential Memorandum of 2015, provides federal employees with six weeks (240 hours) of sick leave after the birth or adoption of a child (ObamaWhiteHouse.archives.gov, 2015). Also, in June 2018, the House of Representatives introduced a new bill-Federal Employees Paid Parental Leave Act - which provided federal employees with access to a minimum of 12 weeks of paid parental leave. These are all different measures aimed at helping American families with raising children. However, there is still no national or universal law mandated by the federal government that would guarantee paid parental leave in an equal way to all employed Americans.

\section{METHODOLOGY}

The study presents a content analysis of online media in regard to their interest in and the coverage of the topic of paid maternity leaves. The Internet sources were chosen as the main sphere of analysis since the Internet is the most frequently used tool when it comes to finding information in today's world. It was in 2008 when the Internet overcame newspapers as the most 
important source of news for Americans (People-Press.org, 2008), so in the analysed years 2014-2018, the world wide web had already been a well-established informative guru. There are many reasons for that, but the most significant one is simultaneously the simplest - the Internet is a very approachable tool, with content available for all Americans who have a phone and Wi-Fi access. In 2009, more than half of the respondents said they preferred the Internet over newspapers, radio or TV as the main news source (Reuters. com, 2009). Additionally, all newspapers, as well as radio and TV stations, have their own websites, on which they post content similar to or the same as the one presented in traditional ways. Thus, because of its accessibility and universalism, the Internet was chosen as the media platform for further analysis. Content analysis - an introduction to its methodology by Klaus Krippendorff (2004) was used as a major source of theoretical knowledge about content analysis. Content analysis methods allowed the author to classify and analyse the collected data according to different themes in order to derive a certain meaning from them.

The time period covered in the analysis spans from the introduction of the Patient Protection and Affordable Care Act ("Obamacare") in 2014 until the end of 2018, after almost two years of Donald Trump's presidency. This choice was not incidental, as the introduction of the Obamacare program provoked public opinion to speak more about parents' rights to paid parental leaves. This topic considered the state's approach to caregiving, which made them closely interconnected. Since 2014, when most of the provisions of the act applied, up to this time, paid maternity leave discourse has become far more popular than before, with Hillary Clinton and Donald Trump popularising it even more during their presidential campaigns. With regard to the choice of material used, both conservative and liberal media outlets were examined to equally understand their opposing views. Thus, the four most popularconservative as well as liberal-media were chosen as examples. These are The New York Times and CNN when it comes to liberal media, as well as Fox News and The Daily Caller, representing the conservative side. All four news websites post their own feed and are the most frequently visited by Internet users in the USA (EBizMBA.com, n.d.). Yahoo and Google, which take first and second places in the ranking, were not taken into consideration, as their feed consists of articles from many different websites. The Huffington Post, which takes the $3^{\text {rd }}$ place, was not considered either as it does not own a convenient search tool on its website, omitting a lot of articles in the search. A separate popularity ranking was used for conservative media as they are not very popular in general rankings among the wider public (Mediashift. com, 2018). Fox News and the Daily Caller turned out to be the most popular among all conservative media. Breitbart was omitted, even though it has $2^{\text {nd }}$ place in the ranking, because it does not have a proper search tool on its website. To sum, up, all chosen websites have content search engines, which were used to find information and articles concerning paid maternity leaves through keywords. 


\section{RESULTS}

In all articles which were considered relevant, paid maternity leave was either the main topic of the article or an important aspect of it. All materials in which paid maternity leave was only mentioned with no analysis or comments were not taken into consideration. All arguments from particular articles were counted and divided into subgroups, depending on their content and attitudes. In general, a total number of 585 articles was found, including $198(33.80 \%)$ in the conservative media and $387(66.20 \%)$ in the liberal media. Around half of them, which amounts to $302(52 \%)$, were relevant and only these were taken into consideration in this study. $283(48 \%)$ articles were irrelevant, meaning paid maternity leave was only mentioned or used as a background to present other issues. The number of relevant articles in liberal media was 234 , whereas, in the conservative media, there were 68 relevant articles; hence, further analysis covered 302 articles. Three main categories were distinguished in terms of the content of these 302 articles: articles with a positive attitude towards paid maternity leaves (248 articles $-82.10 \%$ ), articles with a negative attitude (20 articles $-6.60 \%$ ), as well as neutral articles (34-11.30\%). In liberal media, there were 200 articles $(85.50 \%$ ) with a positive approach towards paid maternity leaves, $9(3.80 \%)$ with a negative overtone, and $25(10.70 \%)$ neutral articles. On the other hand, in conservative media, there were 48 articles $(70.60 \%)$ with a positive attitude towards the leave and $11(16.20 \%)$ with the negative one. The rest ( 9 articles $-13.20 \%$ ) was comprised of neutral articles.

Articles with a positive attitude towards paid maternity leaves could be grouped according to their leading themes into 7 categories:

- pure benefits - the articles praising paid maternity leaves and emphasizing only their positive sides: 18 (6\%) in total, 15 in liberal media, 3 in the conservative ones;

- maternity leave as a human right - articles shaming the U.S. for not providing paid maternity leave benefits as compared to other developed countries: 23 articles (7.6\%), present only in liberal media;

- examples to be followed - presentation of companies and states with successful policies: 78 (25.8\%) articles, 66 in liberal media, 12 in the conservative ones;

- threats and dangers arising from the lack of maternity leaves - articles consisting mostly of real-life stories, when the lack of paid maternity leave had serious or even deadly consequences: 26 articles (8\%), 23 in liberal media, 3 in the conservative ones;

- "paid maternity leaves - united above divisions" - articles with the emphasis on depoliticising the issue, presenting maternity leave as a common interest and calling for an orchestrated, non-partisan action aiming at the introduction of paid maternity leave: 35 of them in general (11.6\%), including 27 in liberal media and 8 in the conservative ones;

- showing paternity leave as an important issue: 8 articles in general $(2.6 \%)$, with 7 in liberal media and 1 in the conservative ones; 
- "yes for maternity leave, but only with our leader" - articles supporting the idea of paid maternity leave but only the version proposed by a specific political leader: $60(19.9 \%)$ of such articles, with 39 in liberal media and 21 in the conservative ones.

Articles with negative attitudes towards paid maternity leaves could be grouped into two categories:

- against the introduction of paid maternity leaves - articles enumerating only negative consequences of leaves: 15 articles (5\%), 7 in liberal media, 8 in the conservative ones;

- marginalising the problem of lack of paid maternity leaves -5 articles $(1.7 \%)$, including 2 in liberal media and 3 in the conservative ones.

There were also neutral, mainly informative articles - 34 (11.3\%) in general, 25 articles in liberal media, and 9 articles in conservative media. Articles categorised as neutral were mostly the ones that presented multiple perspectives on the issue of paid parental leaves. They contained more than one theme, and the authors did not present any clear opinion regarding leaves but rather presented statements of experts by quoting them. In case any attitude towards the leave dominated a given article, it was added instead to the subgroups with leading themes listed above.

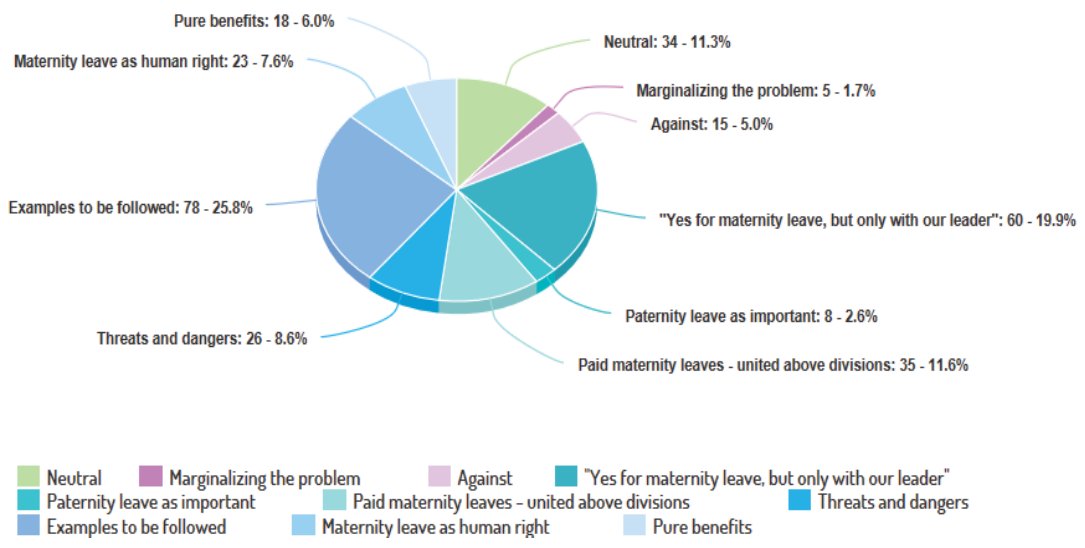

Fig. 1. Articles themes overall

Source: own research.

The highest number of articles in all analysed sources could be observed in 2015 (99 articles - 33\% of all articles), with the exception of Fox News, for which the year 2016 was the most plentiful in relevant content concerning paid maternity leaves. The lowest number of articles could be observed in 2014 (27 articles $-9 \%$ of all articles) when the topic was still evolving. The most popular articles were from the category "examples to be followed" (78 articles - 25.8\% of the whole sample). They were also the most popular in liberal media - 66 of all articles. In conservative media, the most popular articles were "Yes for 
maternity leave, but only with our leader," so the ones affected by political preferences, in which the topic of paid maternity leave served to praise or criticize politicians from a given party, amounting to 21 articles total. It is worth noting that all of these articles were in favour of paid maternity leave. On the other hand, the least popular articles were the ones marginalising the problem of the lack of paid maternity leave, amounting to $5(1.7 \%)$ articles total, 2 of them in liberal, and 3 in conservative media.

The analysis of all selected articles where the topic of paid maternity leave was addressed showed certain patterns of arguments and approaches adopted by the authors. Generally, the articles could be divided according to their positive, negative or neutral attitudes toward paid maternity leaves. The most diverse and numerous category was the group of articles with positive attitudes and that was typical for all analysed media, regardless of their political affiliations. Within this group, seven types of approaches were depicted. The most popular were "examples to be followed" articles, followed by "yes for maternity leave, but only with our leader" type, "paid maternity leave united above divisions" type, articles presenting threats and dangers arising from the lack of maternity leave, the ones showing maternity leave as a human right, "pure benefits" articles, and finally, articles describing paternity leave as important for the mothers' wellbeing. The next section of this work will be focused on describing the main arguments and topics in particular types of articles.

To begin with, the highest number of articles overall were the "examples to be followed" ones, presenting paid maternity leave policies of various companies or other countries as examples that America could follow. Articles included interviews with political leaders and many CEOs of companies like Yahoo, Amazon, Ikea, Facebook, YouTube, Microsoft or Netflix. All of them encouraged companies to introduce paid maternity leaves and showed that it causes better productivity and lowers the stress level of employees. The message reinforced by all articles was that business should face up to its moral responsibilities. Examples of California, New York and Washington states were given, together with Sweden or New Zealand, showing that the introduction of paid maternity leave should be a moral responsibility of world leaders and companies. This type of articles was the most popular in CNN (39 articles) and The New York Times (27 articles), hence in the liberal media. There were 12 such articles in conservative media. In most analysed articles, the "yes for maternity leave, but only with our leader" type was also very popular. In all of them, the idea of the leave itself was treated instrumentally since they were mainly focused on supporting specific leaders and parties and their opinion on specific policies. Their praise or criticism depended heavily on the fact of whose policies they were talking about rather than what policy it was. Articles in more conservative media were supporting the ideas of Donald and Ivanka Trump, meanwhile, articles on the left were advocating for Democratic ideas and criticising Republicans, stating that their proposals would be difficult to introduce and that the benefits would not cover the needs of the poorest Americans. It 
was also stated that Trump's proposal may create even more divisions in the society and a growing gender gap, especially when leaves would be provided only to mothers, not new fathers. This type of articles was popular in both liberal (39 articles), and conservative (21 articles) media, being the leading category in Fox News. The third most popular type - "paid maternity leave united above divisions" - was trying to show that leave is something beyond political boundaries, that both sides of the political arena support the idea of introducing paid maternity leave, and that we are closer than ever to actually introducing it. They were all very encouraging, showing that paid maternity leave debate is much more popular than it was in the past and that any plan is better than no plan. All the arguments were highly positive, unifying, and encouraging different proposals from both left and right political sides. "Paid maternity leave - united above divisions" type was the most popular in The New York Times (19 articles). There were 8 such articles in both CNN and Fox News, and no articles of this type in the Daily Caller. In all the analysed media, there were also many "threats and dangers arising from the lack of paid maternity leave" type of articles. They usually intended to warn readers and present negative consequences of not having paid maternity leave policies in the country. They described mothers who lost their children or had to give up their jobs. A popular argument was that the absence of paid maternity leave in the USA damages the productivity of workers and that there is more and more workplace discrimination, as pregnant women are fired or refused promotion. This type of articles was very popular in the liberal media (23 articles), especially in The New York Times (17 articles). There were almost no such articles in the conservative media (only 3 of them in Fox News). Another article type, "maternity leave as a human right" one, included articles that were using shaming technique showing the USA in a very bad light in comparison to many other countries in the world. The main argumentation in all "maternity leave as a human right" articles was that the USA is backward and underdeveloped in terms of social policies. A lot of comparisons to regulations in Russia, China, or Ukraine were made, not mentioning Western European laws. In general, the message of those articles was that America should be ashamed, as the lack of leave policies is an international disgrace, causing the most modern country in the world to fall behind in case of the most fundamental human rights. There were no "maternity leave as human right" articles in conservative media, with a lot of them in both CNN and The New York Times (the sum of 23 articles). "Pure benefits articles" presented only positive benefits of leaves with arguments that leave policies encourage women to stay at workplaces and help working families to maintain a work-life balance. They also voiced the opinion that the leaves have a huge effect on children's and mothers' health, reduce infant mortality and mothers' depression, encourage vaccinations or doctor's visits. Finally, claims were made that the leaves help boost the economy and eliminate gender gaps. There were 15 such articles in liberal media and only 3 in conservative media. Furthermore, some articles focused on paternity leave, showing that it is important for women's rights and equality at work. They 
encouraged paid paternity leaves, as these would allow both parents to bond with their newly born children and mothers would not be forced to quit their jobs and be out of their workplace for too long after giving birth. There were 7 such articles in liberal media (including 5 in The New York Times) and only 1 in conservative media.

Articles with a negative attitude towards paid maternity leaves could be grouped into two categories. They were either openly against the introduction of paid maternity leaves or they marginalised the issue of non-existing paid leave policies in the USA. Those being against the leave enumerated only the negative consequences thereof. The most popular argument was that employers are not willing to hire or promote women who will be able to take paid time off later on and be less productive than other workers. That is why, authors claimed, paid maternity leave negatively influences the situation of working mothers in the labour market, as they miss out on many career opportunities. This type of articles was the most popular in The Daily Caller (8 articles), with no such articles in Fox News and only 5 of them in liberal media. The articles marginalising the problem used arguments that Congress has more important issues to deal with and citizens do not need more entitlements. The argumentation was that states are doing a very good job, so it is not necessary to solve the problem of paid maternity leave on the federal level. Articles stated that creating sustainable private-sector jobs is more important than introducing the leave, as women can take care of themselves. There were 3 such articles in conservative media and 2 of them in liberal media (all in $\mathrm{CNN}$ ). Finally, among articles categorised as neutral, one could find interviews, facts about the leave, statistics, description of the current state of political affairs, or ways in which one can obtain paid maternity leave benefits in particular states or companies. Informative articles were objective, not suggesting anything or expressing any opinions. They gave readers basic information on how to apply for a leave in a given state for example. There were 9 neutral articles in conservative media and 25 of them in liberal media.

\section{CONCLUSIONS}

To sum up, after analysing all the articles, many tensions in American society reveal themselves. It is not obvious that liberal media are all for the introduction of paid maternity leave, and the conservative ones are against it. In general, it seems that almost the whole society wants the federal government to mandate the leave, but the differences appear in the ideas on how it should be introduced. Also, despite the articles with a positive attitude towards paid maternity leaves, there are many against the leave or marginalising the problem with argumentation that cannot be found, for example, in European media and countries in which paid maternity leave is a natural and obvious entitlement. Given all this, the conclusion part of this paper focuses on describing the possible ideas of why many Americans are still against paid 
maternity leave and why it has still not been introduced to be available universally. As it was already mentioned a few times, in the United States, the policy that would universally mandate paid maternity leave by the federal government for all American citizens does not exist. There are many different acts on the state level and many private companies offer generous benefits, up to even a year of paid leave. Some employees of the public sector are also covered, for example in the military, education, or administration. The FMLA is technically available for all eligible Americans, but it is unpaid and still has many restrictions. Recently, new acts proposed by the Republican Party were introduced, providing up to 3 months of paid parental leave, but they lack in details and have many disadvantages, like jeopardising the retirement benefits. And still, not all parents in all states qualify for it. After analysing the articles in both liberal and conservative media, one may notice that unanimous opinion that paid maternity leave should be introduced does not exist and there are still some voices against the introduction of paid leave benefits for all Americans, which would be comparable to the benefits in other developed countries in the world. However, over $82 \%$ of the analysed articles expressed a positive attitude towards the idea of mandating leaves by the federal government. This number correlates with the Pew Research Centre study from 2016, where 82\% of respondents in America said that women should receive paid leave benefits (PewSocialTrends.org, 2017). Reading this data, one may ask the question of why it has not been introduced yet. The answer can be provided by the same research from the Pew Research Centre, in which about half of respondents claims that the government should obligate employers to introduce leave in their companies. However, the other half does not want the government to regulate it (PewSocialTrends.org, 2017). As it may be noticed, the respondents are highly ambivalent on the desired role of the government. The excerpts from analysed articles show that an important argument against governmental intervention in terms of introducing paid maternity leaves was that the government has more important concerns to take care of nowadays (like introducing sustainable private sector jobs) and that women can handle their problems by themselves, especially that more and more private companies are offering very good benefits for their workers:

Women are not a class of victims that need extra help from the government, conservative leader Sabrina Schaeffer said in response to President Obama's State of the Union Tuesday, which was lauded by some liberals as the first "feminist" address (...) Do we have a wage gap? Yes, a small one that is not the result of widespread discrimination but of women's and men's choices, she continued. Do we have a shortage of paid leave? Sort of. More than 80 percent of full-time workers have access to some paid leave, and 20 percent of part-time workers (Stoltzfoos, 2015).

There were numerous articles against the leave identifies in the analysis. The most popular argument was that employers would not be willing to hire or promote women who take paid time off later on and are less productive because of the child. That is why, authors claimed, paid maternity leave negatively influences the situation of working mothers in the labour market, as 
they miss out on many career opportunities. Articles also suggested that the pay gap is caused by life choices, not sexism or activity of the government, and companies just cannot afford leaves. Moreover, their introduction would be harmful to the economy. According to the articles against the leave, more benefits also mean slow wage growth for employees. Finally, some articles also paid attention to the rights of workers who would have to cover for the work of women on maternity leaves for the same pay. In articles with a negative attitude towards paid maternity leaves, other countries, especially European ones, were often given as examples of the negative consequences of paid leaves:

In Chile, a law requires employers to provide working mothers with child care. One result? Women are paid less. In Spain, a policy to give parents of young children the right to work part-time has led to a decline in full-time, stable jobs available to all women - even those who are not mothers. Elsewhere in Europe, generous maternity leaves have meant that women are much less likely than men to become managers or achieve other high-powered positions at work (Miller, 2015).

The above-mentioned fears expressed in the analysed articles may be confirmed by Sainsbury, one of the authors of Gender and Welfare State Regimes (1996), who claims that the common arguments against introducing paid parental leaves in the USA have been similar since the FMLA bill debate: that all federal regulations would cause excessive costs, that they would be a burden to small businesses, and that excessive governmental interference in the private sector would end the tradition of providing benefits to employees only through labour management contracts. She claims that, historically, both government and business representatives feared that introducing paid parental leaves may harm the international competitiveness of American firms and cause a loss of jobs for many employees (Daly \& Sainsbury, 1996).

In general, public opinion differs strongly when it comes to introducing specific policies, which was visible in the articles analysed in the second part of this work. Americans can see the long-term benefits of paid family leaves and they seem to be convinced that their introduction would pay off in years to come. However, the political system oriented on short-term results as well as hostility toward governmental intervention in this matter seems to be in conflict with long term policies.

Indeed, many researchers confirm this argument in their studies, including Gutman, who claims that since Ronald Reagan's government, Americans' needs in terms of social benefits have been consequently misinterpreted. In other words, she argues that when Ronald Reagan became the president, he concluded his support was caused by the need of Americans to dismantle social welfare provisions in favour of better performance of the economy, which he reflected in his later policies. However, it should not be the case, as Gutman states, because good performance of the economy does not need to depend on reducing the welfare state provisions. However, many Americans still fail to acknowledge that, which causes the problem of paid parental leave in this country (Gutman, 1988). 
In his book Ronald Reagan: The politics of symbolism, Robert Dallek (1999) writes that most American presidents came to power claiming that government that governs less is a better government, but Ronald Reagan had a special fear of governmental intervention. His goal was to reduce the control of the federal government and increase the power of individual citizens instead. He built his career on this idea and made it a centrepiece of his administration. In his inauguration address, he said: "In this present crisis, government is not the solution to our problem; government is the problem" (Dallek, 1999, p. 63). Those traces of past policies and ideas that a better government is a government that spends less on social benefits as it helps the economy are visible in American society until today. The already mentioned survey of Pew Research Center perfectly illustrates this: even though more than $80 \%$ of Americans want to have paid family benefits, around half of them does not want the government to regulate it (PewSocialTrends.org, 2017).

Another argument answering the question of why there is no universal paid parental leave in the USA may be provided by Orloff. In The Politics of Social Policy in the United States, she claims that limitations in social policy initiatives in the USA are caused by incomplete legislation in terms of welfare provisions. The author argues that the reason for this situation can be situated in the past when the first arrangements of the whole state structure were made, as federalism encourages the fragmentation of authority and the division of powers. In other words, the lack of bureaucratic state-building deprives reformers of institutional capacities to perform new social-spending initiatives (Orloff, 1988).

To sum up, the current structure of American social and economic institutions makes it harder for legislators to introduce women-friendly policies. As a consequence, the American government does not have many efficient social policies to help working mothers. What is more, according to Carole Patman, even when there are some, they are poorly designed to help women, as most of them are created taking into consideration only the patriarchal model of a family. Thus, nowadays, when this model is clearly changing, with more mothers becoming primary supporters of the family, some of the existing regulations are simply useless for working mothers, additionally causing their dependency and degradation at the workplace (Gutman, 1988).

It is also important to remember that mothers' well-being is not only about the structure of American institutions, but also about changing the American mindset. Maternity and parenthood are still considered by many as an individual choice and personal responsibility while paid maternity leave is viewed as a form of yet another entitlement that disturbs the market and hurts the business and economy. There is a fundamental conflict between maternity, caregiving and family values, so soundly promoted on the right side of the political scene, and American work culture. In other words, strong individualism, competition, and masculinity of the business culture do not support the values of nurturing and caregiving. Stephanie Coontz (2011), in her A Strange Stirring: The Feminine Mystique and American Women at the Dawn of the 1960s, confirms in her research that being a working mother in the USA is not simple. To illustrate, she develo- 
ped a concept of the so-called "mommy-wars" between working and stay-at-home mothers, which show how challenging it is for Americans to understand that it is possible to combine both parenthood and career. On the basis of interviews conducted with working and stay-at-home mothers, the author concludes that mothers who devote themselves to caregiving work at home are pitied and judged in the United States, especially by mothers who choose a career. As a consequence, stay-at-home mothers are seen as less successful, less effective and unreliable at workplace. And even if they work full time after delivering a child, their co-workers do not trust their effectiveness. For example, Coontz describes an experiment from 2007 in which the researchers at Stanford University created artificial résumés of people applying for a job. The only differences between them were gender and parental status. Then, students ranked all the résumés from best to worst and it turned out that the probability of getting a job by a mother was $79 \%$ smaller than that of fathers or candidates without children at all. The students were also less willing to recommend mothers for promotion and assumed that they would be less punctual than non-mothers, so they were granted a smaller salary as a consequence. In the end, the résumés were delivered to around six hundred employers with real job offers, and it only confirmed the initial conclusions, as childless applicants received twice as many call-backs as parents did. Coontz claims that motherhood stigma exists in America and that it may be the reason why many working mothers do not even expect their employers to offer them maternity leaves. They either quit their job or do not get pregnant at all. Coontz argues that most mothers prefer to be with their newborns instead of working and the family values are very important to both them and their partners. However, the pressure to work is often too strong to focus on family (Coontz, 2011).

Slaughter (2015), American political scientist and former Director of Policy Planning under President Barack Obama, claims in a similar manner that the difficult situation of working mothers is a result of two factors: the culture of overwork in the United States and the assumption that achieving the so-called "work-life balance" is exclusively a woman's issue. She argues that all the social policy "fixes" aimed at achieving equality between men and women at workplace will never truly work, as they are based on "half-truths" about the American workplace. The first wrong assumption is that it is a woman's duty to find time and arrange her caregiving responsibilities. She is the one regarded as a primary caregiver of the family, and a man is regarded as a primary breadwinner. In this situation, employers often assume that there is no need to implement any additional policies, including paid leaves for working mothers, as parents can divide responsibilities between each other by themselves and employers may help only by offering half or part-time work solutions for them as substitutes, without any additional benefits for caregivers. Finally, Slaughter also argues that the problem lies in the so-called "time macho" figure in American business culture. "Time macho" is the one that works the hardest, stays late, and is taking more and more responsibilities at work. A good employee is an employee that aspires to be this macho. Americans praise the figure of an 
effective worker and cause the feeling of guilt in those who do not devote their full time to work and try to achieve work-life balance. Slaughter continues that society imposes certain guilt on women whose main preference is to be with their offspring instead of devoting their lives to career development. As a consequence, they do not ask for time off and employers do not even try to provide them with social benefits, assuming it is not expected from them. The culture of overwork is the reason for people to leave their companies, but managements do not want to recognise this problem. They see it as a one-gender issue only. Slaughter claims that American companies and government fail to adapt to the realities of modern, $21^{\text {st }}$-century American lifestyle, using outdated practices from the $20^{\text {th }}$ century, when only one parent (a husband) was a breadwinner for the family. Finally, according to Slaughter, the problems of a modern American workplace mainly lie in not recognising the source of working parents' issues, not only by employers but also by the government (Slaughter, 2015).

As the author argues, the change of mindset and work culture needs to be preceded by a change in policies. It is visible now that Americans' opinions regarding social provisions are changing. According to 2019 Society at a Glance Report, more than half (57 \%) of Americans wants more governmental intervention in their lives in order to keep them financially secure (OECD.com, 2019). Still, a significant number of respondents is hesitant when it comes to the activity of government in this matter, so new values must be supported and promoted from the above - by legislators and political leaders. It seems that it happens very slowly. Since the end of 2018, different acts regarding leave benefits were proposed in Congress or even introduced and signed into law by POTUS. For example, Republican New Parents Act, CRADLE Act or Democratic FAMILY Act of Senator Kirsten Gillibrand, which is still debated in committees (Time.com, 2019). There was even a bipartisan bill called The Advancing Support for Working Families Act proposed in the Senate (Stefanik.house.gov, 2019). President Trump also approved a 12-week paid parental leave plan for federal workers (SHRM.org, 2019). These are all signs of positive activity in terms of parental benefits for Americans. However, they are only small measures aimed at partial help for families. What is more, all plans have many disadvantages, with a majority of citizens not being able to enjoy the proposed benefits. Most of them are neither easily accessible nor universal and have a very short period of leave with many restrictions regarding payments. The situation gets even more complicated now, in the face of a global pandemic. The coronavirus crisis has drastically shown the lack of basic safety nets for American citizens. Especially now, when many people are losing their jobs and someone needs to take care of children in lockdown, it is more clear that the United States is in contrast with Western developed countries. It simply fails to provide social benefits, including paid parental leaves to its citizens (WTop. com, 2020). The government introduced Families First Coronavirus Response Act, but such a temporary measure simply cannot be a real help for people in need on a long-term basis. It might have seemed for some Americans that their social benefits were sufficient in the past, but they are not enough in the face 
of a current crisis. Nowadays, due to the childcare costs and lack of benefits, having a baby in America has become a luxury. Experts claim that as a result of the pandemic, unstable situation, and poor governmental help, birth-rates in America will continue to drop even further (TheGuardian.com, 2020).

To sum up, public opinion differs, and so does the U.S. Congress, which is debating the issue of paid parental leaves in committees, not agreeing on one common policy that would not increase taxes excessively and would provide the best benefits possible for families at the same time. Anne-Marie Slaughter once wrote:

Here is what we can do. We can take our founding credo - "All men are created equal" - and understand it to mean that men and women are equal and that the work that was once divided between men and women - earning income and providing care - is equally necessary and equally valuable (Slaughter, 2015, p. 246).

Recently, mostly because of COVID-19 and the possibility of economic crisis, both government and American citizens have become involved in the topic of social benefits even more, so it seems like they are ready to catch up with their creed and ideals from the Constitution, so that dreams of many parents may finally become reality. It also seems that Americans' changing needs are reflected in the outcome of the 2020 presidential elections and the welfare state-friendly program of Joe Biden. His proposal involves introducing paid parental leaves for working parents (for the duration of 12 weeks) and more affordable childcare. It seems that paid parental leaves and social benefits may become an important topic in 2021 political agenda (Marcoux \& Orsini, 2021).

\section{REFERENCES}

[1] Berger, L. M., Hill, J., \& Waldfogel, J. (2005). Maternity leave, early maternal employment and child health and development in the US. The Economic Journal, 501(115), 29-47.

[2] Babcock, L., \& Laschever, S. (2003). Women don't ask: Negotiation and the gender divide. Princeton: Princeton University Press.

[3] BLS.gov. (2020). Employer Cost for Employee Compensation. Retrieved March 19, 2020, from https://www.bls.gov/news.release/ecec.toc.htm.

[4] Coontz, S. (2011). A strange stirring: The feminine mystique and American women at the dawn of the 1960s. New York: Basic Books.

[5] Crittendon, A. (2001). The price of motherhood: Why the most important job in the world is still the least valued. New York: Henry Holt and Company, LLC.

[6] Dallek, R. (1999). Ronald Reagan: The politics of symbolism. Cambridge: Harvard University Press.

[7] Daly, M., \& Sainsbury, D. (1996). Gender and welfare state regimes. Oxford: Oxford University Press.

[8] EBizMBA.com. (n.d.). Top 15 most popular news websites. Retrieved January 1, 2019, from http://www.ebizmba.com/articles/news-websites.

[9] Gutman, A. (1988). Democracy and the welfare state. Princeton: Princeton University Press.

[10] Hirshman, L. (2006). Get to work: A manifesto for women of the world. New York: Viking Books.

[11] Jacobs, J. A., \& Gerson, K. (2004). The time-divide: Work, family, and gender inequality. Cambridge: Harvard University Press.

[12] Klerman, J. A., \& Leibowitz, A. (1999). Job continuity among new mothers. Demography, 36(2), $145-155$. 
[13] Krippendorf, K. (2004). Content analysis - An introduction to its methodology. London: SAGE Publications.

[14] Marcoux, H., \& Orsini, J. (2021). What Joe Biden's win means for moms. Mother.ly. Retrieved February 17, 2021, from https://www.mother.ly/news/ what-joe-biden-win-would-mean-for-moms/joe-bidens-plan-for-childcare.

[15] McBride, D. E., \& Parry, A. (2004). Women's rights in the USA: Policy debates and gender roles. New York: Thomson Brooks.

[16] Mediashift.com. (2018). Who gets the most traffic among conservative websites? Retrieved January 18, 2018, from http:/ / mediashift.org/2018/01/nine-insights-right-wing-website-traffic/.

[17] Miller, C. C. (2015). When family-friendly policies backfire. The New York Times. Retrieved February 17, 2021, from https://www.nytimes.com/2015/05/26/upshot/when-family-friendly-policies-backfire.html?searchResultPosition=1.

[18] Moen, P., \& Roehling, P. (2005). The career mystique: Cracks in the American dream. Lanham: Rowman \& Littlefield Publishers.

[19] NCSL.org. (n.d.). State Family and Medical Leave Acts. Retrieved February 17, 2021, from http:// www.ncsl.org/research/labor-and-employment/state-family-and-medical-leave-laws.aspx.

[20] OECD.com. (2019). Society at glance 2019. Retrieved February 17, 2021, from http://www. oecd.org/unitedstates/sag2019-united-states.pdf.

[21] OPM.gov. (n.d.). Fact Sheet: Family and Medical Leave. Retrieved February 17, 2021, from https://www.opm.gov/policy-data-oversight/pay-leave/leave-administration/ fact-sheets/family-and-medical-leave/.

[22] Orloff, A. S., Skocpol, T., \& Weir, M. (1988). The politics of social policy in the United States. Princeton: Princeton University Press.

[23] Parents.com. (n.d.). Maternity leave by state: Learn your rights. Retrieved February 17, 2021, from https://www.parents.com/pregnancy/my-life/maternity-paternity-leave/ how-does-your-state-measure-up-on-maternity-leave/.

[24] People-Press.org. (2008). Internet overtakes newspapers as news outlet. Retrieved February 17, 2021 from www.people-press.org/2008/12/23/internet-overtakes-newspapers-as-news-outlet/.

[25] PewSocialTrends.org. (2017). Americans widely support paid family and medical leave, but differ over specific policies. Retrieved February 17, 2021, from https://www. pewsocialtrends.org/2017/03/23/americans-widely-support-paid-family-and-medicalleave-but-differ-over-specific-policies/.

[26] Reuters.com. (2009). Internet most popular information source: Poll. Retrieved February 17, 2021 from https:/ / www.reuters.com/article/us-media-internet-life-idUSTRE55G4XA20090617.

[27] SHRM.org. (2019). Trump approves paid parental leave for federal workers. Retrieved February 17, 2021, from https:/ / www.shrm.org/resourcesandtools/legal-and-compliance/employment-law/pages/trump-approves-paid-parental-leave-for-federal-workers.aspx.

[28] Slaughter, A. M. (2015). Unfinished business. New York: Random House.

[29] Statista.com. (2020).Averagefull-wageequivalentweeksofpaidleaveavailabletomothersin OECD countries in 2016. Retrieved February 17, 2021, from https://www.statista.com/statistics/916711/ oecd-countries-average-full-wage-equivalent-weeks-paid-maternity-leave/.

[30] Stefanik.house.gov. (2019). Stefanik, Allred, Cassidy, Sinema, introduce bipartisan bill supporting parents in critical first year following births, adoptions. Retrieved February 17, 2021, from https://stefanik.house.gov/media-center/press-releases/stefanik-allred-cassidy-sinemaintroduce-bipartisan-bill-supporting.

[31] Stoltzfoos, R. (2015). IWF toObama:Womendon'tneed a savior. The Daily Caller. Retrieved February 17, 2021, from https:/ / dailycaller.com/2015/01/21/iwf-to-obama-women-dont-need-a-savior/ .

[32] TheGuardian.com. (2020). In America, having a baby is becoming a luxury only a few can afford. Retrieved February 17, 2021, from http:/ / www.theguardian.com/commentisfree/2020/may/23/america-children-parents-week-in-patriarchy.

[33] Time.com. (2019). Paid family leave has stalled in Congress for years. Here's why that's changing. Retrieved February 17, 2021, from http:/ / time.com/5562960/paid-family-leave-congress/.

[34] WTop.com. (2020). Pandemic shows contrasts between US, European safety nets. Retrieved February 17, 2021, from https://wtop.com/coronavirus/2020/05/pandemic-shows-contrastsbetween-us-european-safety-nets/. 